\title{
SEEIIST
}

\section{SOUTH EAST EUROPEAN INTERNATIONAL INSTITUTE FOR SUSTAINABLE TECHNOLOGIES}

\author{
- Sanja Damjanovic ${ }^{1,2,3}$ on behalf of the Intergovernmental SEEIIST Steering Committee ${ }^{4}$ \\ v ${ }^{1}$ Ministry of Science of Montenegro, Montenegro $-{ }^{2}$ GSI Helmholtzzentrum für Schwerionenforschung, Darmstadt, Germany \\ ${ }^{3}$ Chairperson of the SEEIIST Steering Committee $-{ }^{4}$ https://seeiist.eu/members - DOI: https://doi.org/10.1051/epn/2019404
}

\section{The states in South East Europe are joining forces to set up a large-scale competitive research infrastructure - the South East European International Institute for Sustainable Technologies (SEEIIST, https://seeiist.eu). Due to the recent history in South East Europe all scientific and economic activities have very much slowed down. As a consequence this region has suffered ever since from a strong brain drain of the young generation, affecting in particular the best.}

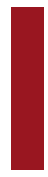

$\mathrm{n}$ contrast, the same region had in the past an intensive technological development and made significant scientific contributions on an European scale. Prime examples are the first research nuclear reactor in this region operated already in 1959, just two years after such a research reactor started operation in Germany, and the role of the region as one of the founding members of CERN in 1954. To recover this tradition, i.e. to decrease the present large gap compared to the rest of Europe and to revert the brain drain, the most efficient way is to establish a large-scale internationally competitive research infrastructure in South East Europe.

The objective of this project is to foster regional cooperation in the fields of science, technology and industry in the spirit of the CERN and SESAME models 'Science for Peace. This would greatly help to address common challenges and needs in SEE, helping in particular to develop sustainable economy and social cohesion. Capacity building and the slowing down if not reversal of the brain drain would become immediate benefits.

About two years ago the Government of Montenegro initiated the establishment of the SEEIIST Project, originally proposed by Prof. Herwig Schopper, a former Director General of CERN. This Initiative was formalized as a Regional project after signing a Declaration of Intent on 25 October 2017 at a Ministerial meeting at CERN (Figure 1, top). The Signatory Parties were Albania, Bosnia and Herzegovina, Bulgaria, Kosovo ${ }^{1}$, Montenegro,

\footnotetext{
${ }^{1}$ This designation is without prejudice to positions on status and is in line with UNSC 1244/1999 and the ICJ opinion on the Kosovo Declaration of Independence
}

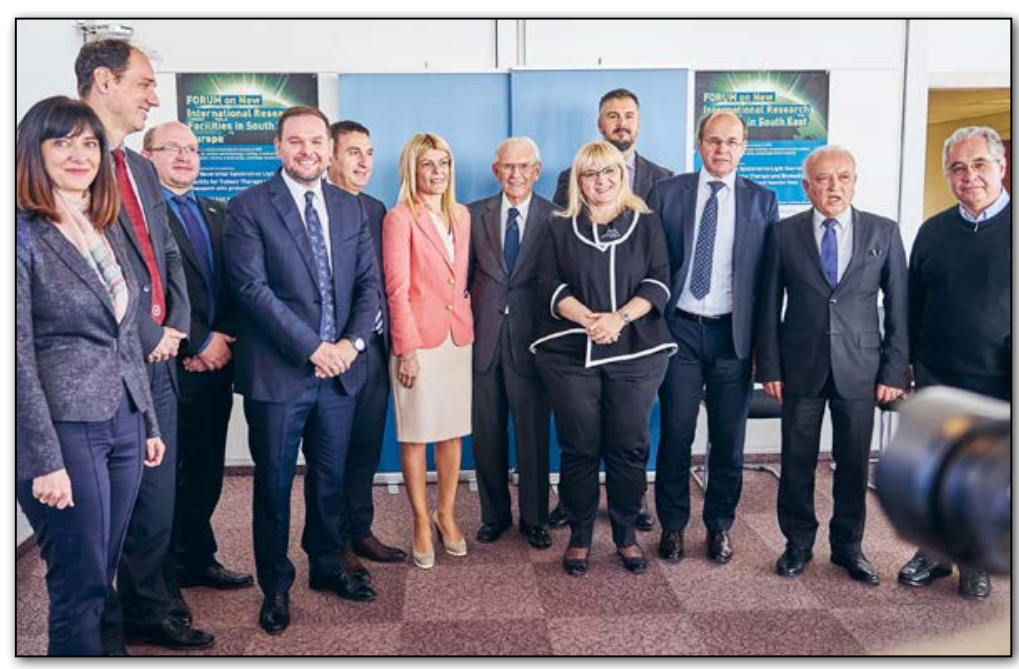

FIG 1: Signature of Declaration of Intent at CERN by Ministers of Science/Corresponding Ministers (top); Signature of Memorandum of Cooperation by Prime Ministers of the Region at the Summit of the Berlin Process at Poznan (bottom).

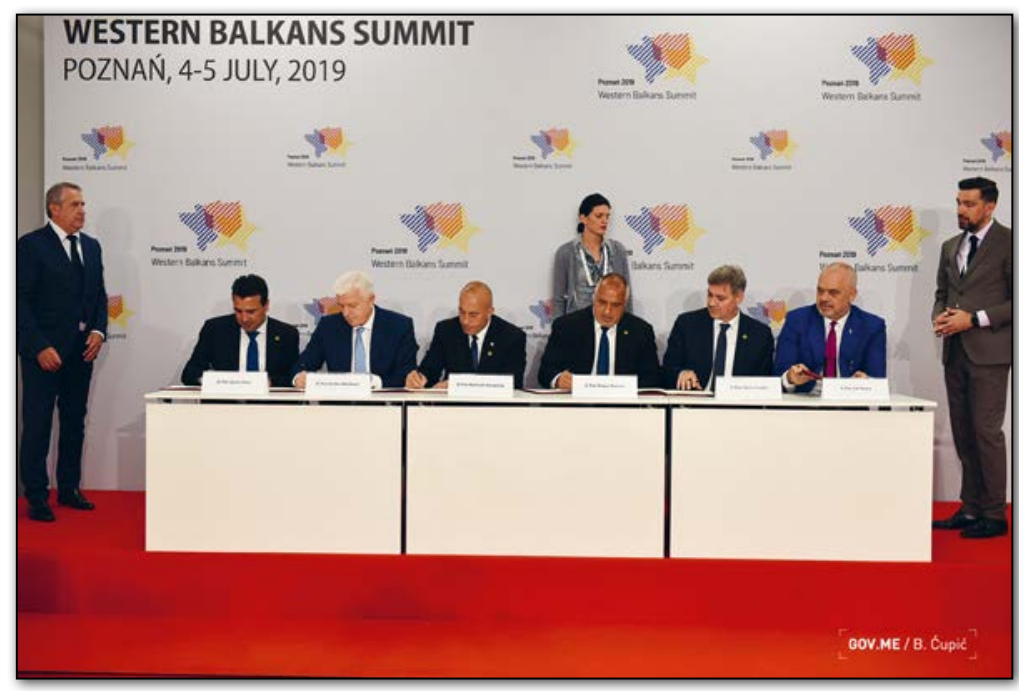


